\title{
Ascaris infestation leading to diarrhea and malnutrition
}

\author{
Sushil Khanal ${ }^{1}$, Sarina Maharjan², Diptesh Aryal $^{3}$, Subhash Prasad Acharya ${ }^{4}$ \\ Abstract \\ Gastrointestinal infestation with Ascaris lumbricoides is common in the tropical countries. A wide range of clinical \\ presentations are reported for gastrintestinal ascariasis in both adults and children. We report a case of diarrhea \\ causing malnutrition in ICU due to Ascaris infestation.
}

Key words: Ascaris, Diarrhea, Malnutrition.

\section{Introduction:}

Ascaris lumbricoides is the most common helminth affecting humans and causing important medical and social problems especially in the under-developing countries. A wide range of clinical presentations are reported for GI ascariasis in critically ill patients in Intensive Care Unit (ICU). ${ }^{1}$ We report here a case of diarrhea leading to malnutrition in ICU due to gastrointestinal infestation with Ascaris lumbricoides.

\section{Case report:}

A 32 years old man presented in Emergency room with alleged history of Road traffic accident causing severe head injury with multiple contusions with subdural hematoma and extradural hematoma. The patient was received in our ICU following craniotomy with evacuation of hematoma. Nutrition parameters on admission were as follows: weight 60 $\mathrm{kg}$; height160 cm; and a BMI $23.43 \mathrm{~kg} / \mathrm{m} 2$. The full caloric enteral nutritional support was started within first 48 hours of ICU admission via orogastric feeding. The patient was tracheostomised early considering the need of prolonged ventilation. After one week of ICU stay patient started to have multiple episodes of loose motion. Routine stool analysis for ova and parasite, stool cultures, C. difficile assay in addition to blood and urine cultures were all negative. Abdominal ultrasound was done and it was unremarkable. We evaluated for all potential infectious and noninfectious causes of

1. Dr. Sushil Khanal, MD, Grande International Hospital (GIH), Kathmandu, Nepal

2. Dr. SN Sarina Maharjan, Grande International Hospital (GIH), Kathmandu, Nepal

3. Dr. Diptesh Aryal, MD, FACC, Grande International Hospital (GIH), Kathmandu, Nepal

4. Dr. Subhash Prasad Acharya, MD, FACC, FCCP, Grande International Hospital (GIH), Kathmandu, Nepal

\section{Corresponding Author:}

Dr. Sushil Khanal

$\mathrm{MD}$, Anaesthesiologist

Grande International Hospital (GIH)

Kathmandu, Nepal

Phone: +977-9843177465

Email:khanaliom@gmail.com diarrhea for this patient but the underlying cause could not be identified. Parenteral nutrition was started as supplement to enteral nutrition to meet the energy requirement of the patient. Patient's condition did not improve and progressively worsened, with the increase in volume and frequency of diarrhea. He lost around 15 kilograms during 2 weeks period. On physical examination, the patient was a cachectic young man with normal vital signs. After 2 weeks of ICU stay there was spontaneous expulsion of round worm in the patient's stool, then worm was sent for investigation and diagnosed as Ascaris lumbricoides. The worm was male, cylindrical in shape with curved end, $15 \mathrm{~cm}$ in length and 2 to $4 \mathrm{~mm}$ in diameter.[Fig-1] A good recovery of patient was noticed with cessation of diarrhea and gradual weight gain after treatment with albendazole.

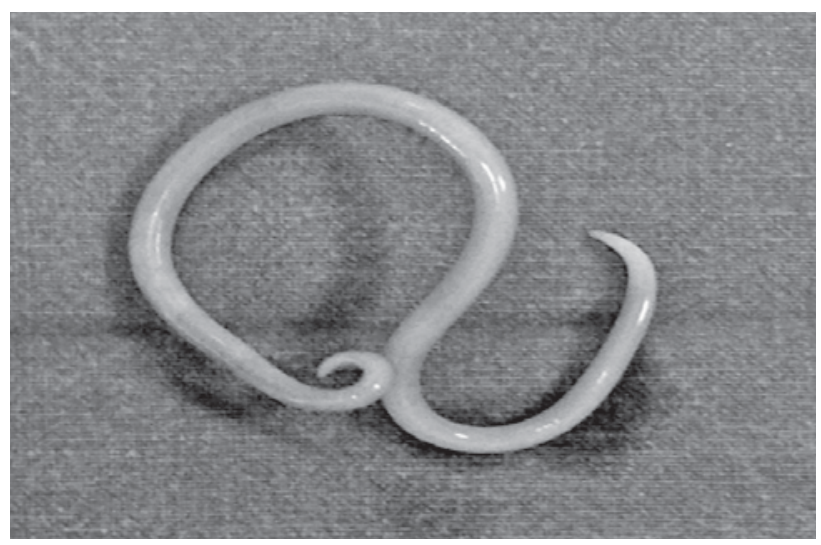

Fig. 1: Ascaris Lumbricoides

\section{Discussion:}

Ascariasis is a world-widely distributed parasitic infection, especially in tropical and subtropical areas where unhygienic disposal of human excreta is common. The mode of A. lumbricoides infection is by the ingestion of embryonated eggs in raw vegetables, water or soil-contaminated hands. The fertilized eggs hatch in the intestine. The released larvae penetrate the intestinal wall to reach the right side of the heart, pulmonary circulation and then to the alveoli. When the larvae are coughed up by the host, they are swallowed back into the intestine to develop into adult worms. ${ }^{2}$

The clinical features of A. lumbricoides infection are variable between asymptomatic and symptomatic disease depending upon the parasitic burden. ${ }^{3}$ Heavy infection with Ascaris 
lumbricoides is frequently manifested by abdominal discomfort, anorexia, nausea and diarrhea leading to protein malnutrition and vitamin A deficiency. ${ }^{4,5}$ Adult worms cause serious clinical problems during their migration, including acute pancreatitis, acute cholecystitis, liver abscess, intestinal obstruction when present in large numbers and even perforation. The management of the majority of cases of uncomplicated ascariasis can be done successfully with antiparasitic drugs such as albendazole, mebendazole or pyrantel pamoate. ${ }^{2}$

The prevalence of diarrhea in critically ill patients ranges between 14 and 21\%. Diarrhoea in the critically ill be defined as the simultaneous presence of stool frequencies three stools per day or more, with stool weights $200 \mathrm{~g}$ /day or higher and consistency of stools categorized as $5-7$ on the Bristol Stool Chart. The majorities of patients with diarrhea require only supportive care with replacement of fluids and electrolytes and close monitoring of laboratory values and organ function. It is always essential to exclude, or confirm and treat infectious diarrhea. ${ }^{6}$ There is little evidence to support delaying or withdrawing provision of enteral nutrition in patients with diarrhea. ${ }^{7,8}$ Probiotics and prebiotics can possibly reduce diarrhoea, but there are not enough data to recommend their routine use in critically ill patients. ${ }^{9,10}$ The consequences of diarrhea like hypovolaemia, electrolyte disturbances, malnutrition, skin lesions and contamination of wounds - should be avoided or at least recognized promptly. ${ }^{6}$ Although not definitively proven, it is very likely that diarrhoea has an impact on the risk of complications in ICU patients, as well as on the workload and costs. ${ }^{11}$

In our case, we determined the underlying cause of diarrhoea leading to malnutrition as Ascaris lumbricoides. Diagnosis of ascariasis must be sought in endemic areas as soon as possible when faced with persistent diarrhea in critically ill patients in ICU. Timely diagnosis, antihelmintic therapy and supportive care will result in an excellent outcome for the affected patient.

\section{References:}

1. Chawla A, Patwardhan V, Maheshwari M. Primary ascaridial perforation of the small intestine: Sonographic diagnosis. J Clin Ultrasound. 2003, 31: 211-213.

2. Abdellatif MZ, Belal US, Abdel-Hafeez EH, Atiya AM, Norose K. Ascaris lumbricoides causing acute abdomen: a case report. East Mediterr Health J. 2013 Dec;19(12):1035-7.

3. Dold C, Holland CV. Ascaris and ascariasis. Microbes Infect. 2011, 13:632-637

4. Stephenson LS, Latham MC, Ottesen EA. Malnutrition and parasitic helminth infections. Parasitology, 2000, 121(Suppl.):S23-S38.

5. Crompton DW, Nesheim MC. Nutritional impact of intestinal helminthiasis during the human life cycle. Annual Review of Nutrition, 2002, 22:35-59.

6. Reintam Blaser A, Deane AM, Fruhwald S. Diarrhoea in the critically ill. Curr Opin Crit Care. 2015 Apr;21(2):142-53.

7. Montejo JC, Grau T, Acosta J, Ruiz-Santana S, Planas M, García-De-Lorenzo A et al. Multicenter prospective randomized single-blind study comparing the efficacy and gastrointestinal complications of early jejunal feeding with early gastric feeding in critically ill patients. Crit Care Med 2002; 30:796-800.

8. Davies AR, Morrison SS, Bailey MJ, Bellomo R, Cooper DJ, Doig GS, et al. A multicenter, randomized controlled trial comparing early nasojejunal with nasogastric nutrition in critical illness. Crit Care Med 2012; 40:2342-2348.

9. Theodorakopoulou M, Perros E, Giamarellos-Bourboulis EJ, Dimopoulos G. Controversies in the management of the critically ill: the role of probiotics. Int J Antimicrob Agents 2013; 42 (Suppl):S41-S44.

10. Chang SJ, Huang HH. Diarrhea in enterally fed patients: blame the diet? Curr Opin Clin Nutr Metab Care 2013; 16:588-594

11. Thibault R, Graf S, Clerc A, Delieuvin N, Heidegger CP, Pichard C. Diarrhoea in the ICU: respective contribution of feeding and antibiotics. Crit Care 2013; 17:R153. 